\title{
Measurements on Solar Energy Resources in the Mt. Everest Region
}

\author{
Norsang Gelsor ${ }^{1}$, Liu Juan ${ }^{1, ~ *, ~ T s o j a ~ W a n g m o ~}{ }^{1}$, Lagba Tunzhup ${ }^{1}$, Nuozhen Gelsor ${ }^{2}$ \\ ${ }^{1}$ Geophysics Institute, Tibet University, Lhasa, China \\ ${ }^{2}$ Department of Physics and Technology, University of Bergen, Bergen, Norway \\ Email address: \\ 422575093@qq.com (Liu Juan) \\ ${ }^{*}$ Corresponding author
}

To cite this article:

Norsang Gelsor, Liu Juan, Tsoja Wangmo, Lagba Tunzhup, Nuozhen Gelsor. Measurements on Solar Energy Resources in the Mt. Everest Region. American Journal of Physics and Applications. Vol. 9, No. 1, 2021, pp. 1-9. doi: 10.11648/j.ajpa.20210901.11

Received: December 17, 2020; Accepted: January 5, 2021; Published: January 15, 2021

\begin{abstract}
Research on solar radiation in the Mt. Everest region provides great interests for the strategies of solar energy utilization, climate change and environmental sustainability etc. We present measurement results of global horizontal irradiance, solar spectral irradiance and solar UV irradiance performed with the Dutch CMP11 Pyranometers, the German RAMSES Hyperspectral Irradiance Sensors and the Norwegian NILU-UV Irradiance Meters respectively in the Mt. Everest region during 2008 to 2017. The results show that the solar energy resources are extremely rich in that area, the daily maximum of global horizontal irradiance levels are even frequently exceed the solar constant value of $1368 \mathrm{~W} / \mathrm{m}^{2}$ during monsoon season, from May to August in that region. The highest daily maximum value reached $1500 \mathrm{~W} / \mathrm{m}^{2}$ occurred on July 13, 2017. The annual average of the daily global horizontal irradiance is about $18.4 \mathrm{MJ} / \mathrm{m}^{2} / \mathrm{d}$, the daily global horizontal irradiance varies from 13.8 to 23.9 $\mathrm{MJ} / \mathrm{m}^{2} / \mathrm{d}$, indicates that there are abundant solar energy in that alpine zone. The instruments record that even during the winter time (October to January) more than 15 days of each month are absolute clear days, it shows 28 clear days in November of 2016. It points out that more solar energy can be existed during the winter time due to dry season. The solar spectral irradiance was performed for the first time in this special environment presenting the characteristics of solar spectrum over the region. It reveals not only how abundant the spectral irradiance is, but also rich information about the atmospheric composition over the sky. It is well known that the solar UV radiation strongly impacts on the ecological environment and human health. The measurement results of solar UV dose rates as well as their impact factors (ozone and cloud) during the period of 2008 to 2017 are also presented. Satellite data are also used to see how the solar irradiance is distributed over the Himalayan region in summer, including Mt. Everest.
\end{abstract}

Keywords: Solar Energy, Mt. Everest, Global Horizontal Irradiance, Solar Spectral Irradiance, Solar UV Radiation

\section{Introduction}

Solar energy in the Mt. Everest region is great interests for the people living in that area due to the lack of traditional energy resources. Solar energy is radiant light and heat from the Sun. The solar energy receiving on the Earth's surface depends on the geographical position and atmospheric conditions [1]. In the Himalayan region, there are rich solar energy resources in theory. In recent years, many scholars have been conducting surface measurements and in-depth analysis on the resources of the ground solar radiation in many places of the world to see how the solar energy resources are distributed spatially and changed temporally. The studies found that the surface solar radiation in most regions of the world decreases significantly in some periods and increases in some other periods [2-3]. In the Himalayan region, researchers both from Nepal and Tibet are doing measurements on global solar irradiance, solar UV irradiance and their impact factors through ground and Satellite observations. Scientists from Nepal have published their findings on many journals [4-6], the findings are mainly focused on surface global solar irradiance, solar UV 
irradiance and their impact factors [7-11]. The same studies have also been curried out over the Tibetan Plateau since 1996, the relevant research results were published internationally [12-16].

However, for the time been, little studies on the solar energy measurements are available for the The Mt. Everest area due to its difficult conditions for observations. In this paper, we mainly focused on the ground-based measurements of global horizontal irradiance, solar spectral irradiance, solar UV irradiance and their impact factors in Mt. Everest Region of Tibetan side. The measurements were curried out during Oct 2008 to Dec 2017. The current studies could provide surface data for many relevant fields like utilization of solar energy resources as well in that particular region.

\section{Methods}

\subsection{Observation Site}

Solar observation station is located in Tibetan side of the Mt. Everest, at the Meteorological Bureau of Tingri county $\left(28.655516^{\circ} \mathrm{N}, 87.129036^{\circ} \mathrm{E}\right.$, Alt. $\left.4335.0 \mathrm{~m}\right)$. The distance from the station to the base camp of Mt. Everest is about 60 $\mathrm{km}$. The instruments are installed at a top of a highly satisfied building and the surrounding environment is as seen in Figure 1.

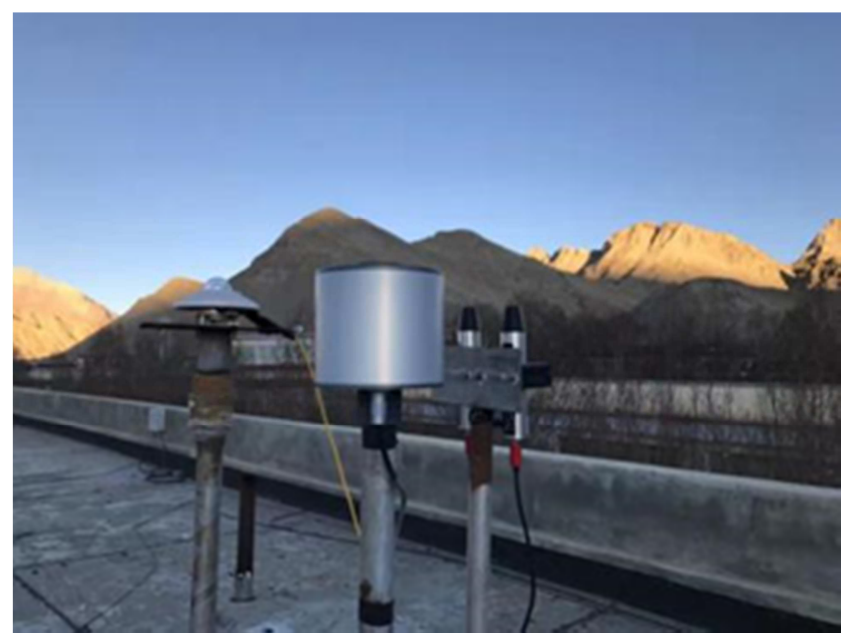

Figure 1. Solar radiation Observation Site near the Mt. Everest, Tibet.

The station is actually located in a mountain valley with valley width around $3 \mathrm{~km}$. The heights of nearby mountains are about 200 meters, no snows except some short periods in winter time, mostly bare rocked mountains. The mountains in East and west can affect observation time in the morning and evening, in different seasons the effects are different. The weather condition in this region is typical plateau climate, belongs to the plateau temperate semi-arid monsoon climate zone. It has large temperature difference between day and night, dry climate, small annual rainfall, large evaporation, and long sunshine duration, strong ultraviolet radiation, the annual average temperature is only $2.8 \sim 3.9$ degrees Celsius.

\subsection{Observation Instruments}

We use the RAMSES Hyperspectral UV Sensor and Hyperspectral UV-VIS Radiance Sensor produced by German TriOS company to observe solar spectrum on 24th January, 2017 for the first time ever in this region. The global horizontal irradiance on a horizontal surface during 2016 to 2017 were measured by using a CMP11 Pyranometer produced by Holland Kipp and Zonen company. A NILU-UV Irradiance Meter produced by Norwegian NILU-AS company is used to measured solar UV irradiance and its impact factors during the 2008 to 2017.

\subsubsection{RAMSES Hyperspectral Sensors}

The RAMSES Hyperspectral Sensors are stand-alone and highly integrated hyperspectral radiometers for solar UV and solar visible radiation spectral range. Small size and very low power consumption make them suitable for hand-held and autonomous applications. RAMSES-ACC-UV is used to measure the down-ward UV spectral irradiance. The spectral range is from $280 \mathrm{~nm}$ to $400 \mathrm{~nm}$, spectral accuracy is $0.2 \mathrm{~nm}$, measurement wavelength interval is $2.2 \mathrm{~nm} / \mathrm{pixel}$. RAMSES-ACC-UV-VIS's spectral range is from $320 \mathrm{~nm}$ to $950 \mathrm{~nm}$, spectral accuracy is $0.3 \mathrm{~nm}$, measurement wavelength interval is $2.2 \mathrm{~nm} / \mathrm{pixel}$. The operating temperature for the both instruments is from $-10^{\circ} \mathrm{C}$ to $50^{\circ} \mathrm{C}$, spectral irradiance value are measured every minute. A description of instrument performance is given in TriOS. Ramses Hyperspectral radiometer manual. RAMSES-ACC-UV was calibrated with the NIST standard lamp (DXW-1000W, 120V) on 15 September 2016, RAMSES-ACC-VIS was calibrated with the NIST standard lamp (DXW-1000 W, $120 \mathrm{~V}$ ) on 22 August 2016.

\subsubsection{CMP6 Pyranometer}

The CMP11 pyranometers have wide spectral range of $285 \mathrm{~nm}$ to $2800 \mathrm{~nm}$. The operating temperature is from $-40^{\circ} \mathrm{C}$ to $+80^{\circ} \mathrm{C}$. The sensitivity of the instrument is from 7 to 14 $\mu \mathrm{V} / \mathrm{W} / \mathrm{m}^{2}$. All the measuring data are recorded by LOGBOX $\mathrm{SD}$ data logger within a minute resolution for 24 hours. Its special features are low noise, high resolution and low power consumption. It can be used in all weather conditions. The instrument specification can be found in Kipp and Zonen, "Instruction Manual". The instruments were calibrated against a reference radiometer of similar type according to ISO 9847:1992 'Solar Energy-Calibration of field pyranometers' at the Kipp and Zonen factory on 27 June 2016. The reference radiometer is calibrated outdoors regularly at the World Radiation Centre (WRC) at Davos, Switzerland.

\subsubsection{NILU-UV Irradiance Meter}

The NILU-UV instrument has six wavelength channels, and is designed to measure the hemispherical irradiance on a flat surface. Five of the channels are in the UV spectral range with center wavelengths at $305,312,320,340$, and 380nm, each with a bandwidth of about 10nm FWHM (Full-Width-at-Half-Maximum). The sixth channel covers 
wavelengths in the visible range, i.e. between 400 and $700 \mathrm{~nm}$. The data logger of the NILU-UV instrument records one-minute averages for every minute. A description of instrument performance is given in Høiskar et al. [17], and the instruments were absolutely calibrated against a Bentham D150 high-wavelength resolution spectroradiometer at the Norwegian Radiation Protection Authority (NRPA) in Oslo and the relative calibrations are carried out in Lhasa every ten days, the methodology of data analysis is described in Dahlback [18].

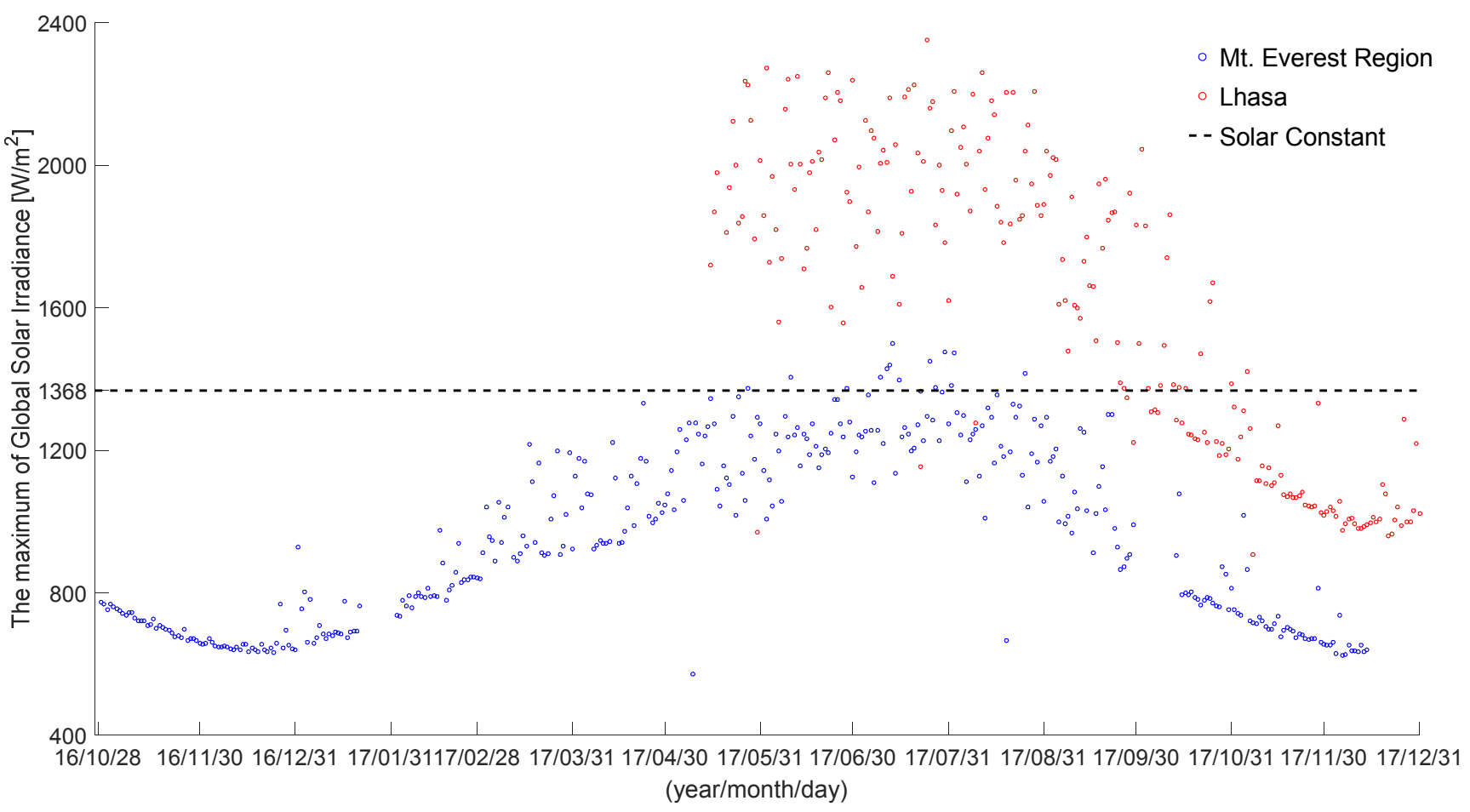

Figure 2. The daily maximums of global horizontal irradiance in the Mt. Everest Region and Lhasa.

Figure 2 shows the variation of diurnal maximum of global horizontal irradiance (flux density) from 2016 to 2017. It shows large values (larger than $600 \mathrm{~W} / \mathrm{m}^{2}$ ) of global horizontal irradiance in that region through the whole years. It can be seen from the figure that the diurnal maximum of global horizontal irradiance of Lhasa is obviously higher than that of Mt. Everest. During the measurement period, the diurnal maximum of global horizontal irradiance of Lhasa from May to October almost exceeded the solar constant of $1368 \mathrm{~W} / \mathrm{m}^{2}$ (the dashed line), with the maximum reaching $2352 \mathrm{~W} / \mathrm{m}^{2}$, on July 24, 2017. It depicted that the diurnal maximum of global horizontal irradiance of Mt. Everest Region exceeds the solar constant mainly during May to August. The highest value of the daily flux density recorded was $1500 \mathrm{~W} / \mathrm{m}^{2}$ appeared in the summer, on July 13, 2017. Such high values are caused both by the high altitude and so called cloud enhancement under the circumstances of debris clouds over the sky, but the solar disk

\section{Results and Discussions}

\subsection{Global Horizontal Irradiance in Mt. Everest Region}

We present measurements results of the global horizontal irradiance from Oct. 28, 2016 to Dec. 31, 2017 in the Mt. Everest Region and May. 152017 to Dec. 31, 2017 in Lhasa. Although the CMP11 pyranometers record data within one minute resolution for 24 hours, we selected the daily maximum values only to show how the maximums of global horizontal irradiance changes with days and seasons, as seen in Figure 2. is not blotted out. Figure 2 also shows that the global horizontal irradiance are changed substantially with the seasons. It shows that the irradiance values are centralized almost in a single curve during winter time, not scattered each other. However, during summer time the values are apart from each other, this enhancement or attenuation are mainly caused by the broken clouds in the monsoon seasons. There are plenty of clear days in the winter time, which means rich solar energy resources over that region.

Figure 3 shows recorded absolute clear days (not a single cloud during a day) during the measurement period. The maximum clear day number of Mt. Everest Region is 28 and The maximum clear day number of Lhasa is 21 in November, 2016, the others are seen in the Figure 3. However, in the summer, there are very few sunny days, even zero clear days in May and August in 2017. 


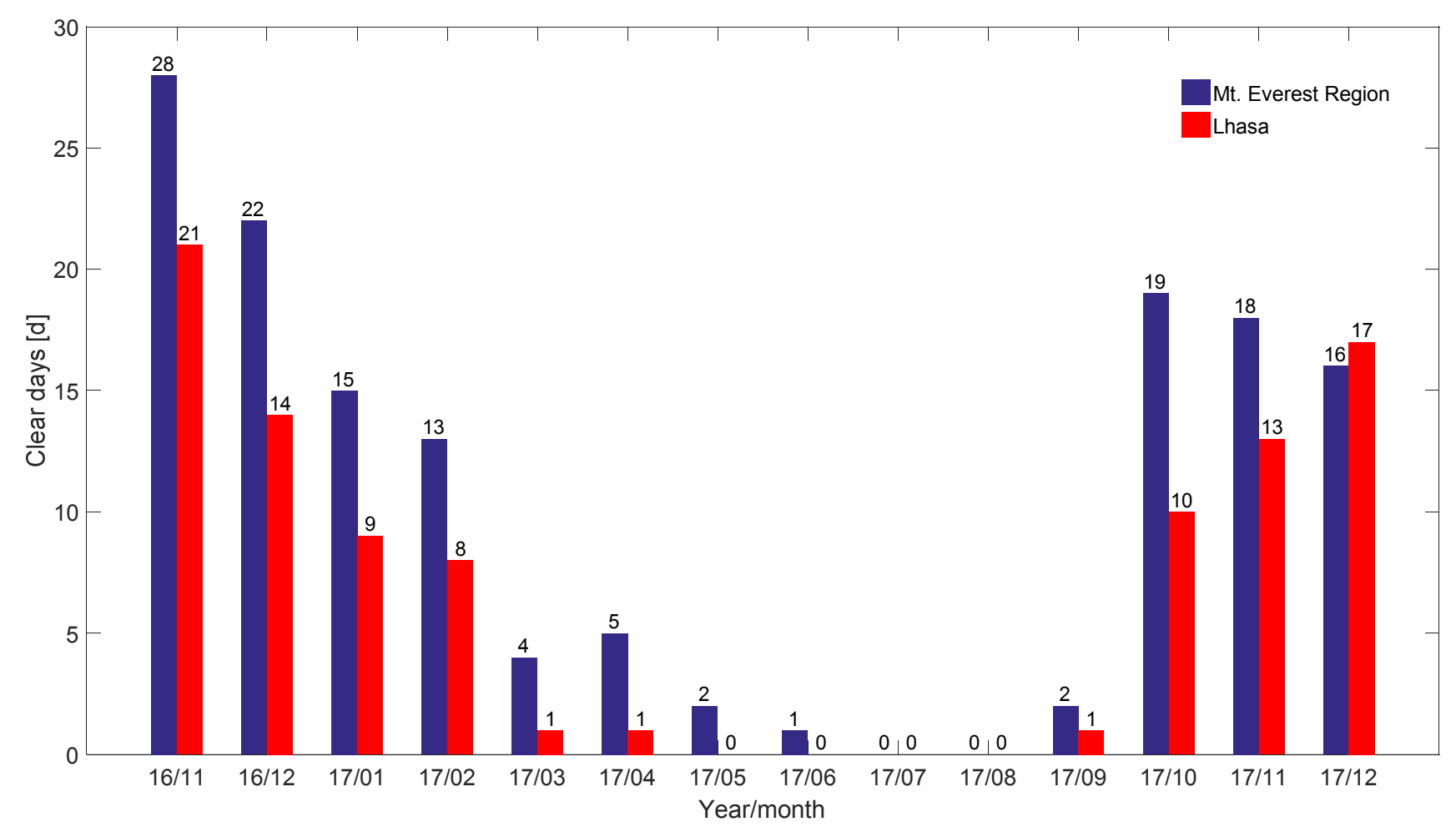

Figure 3. Number of clear days in a month in the Mt. Everest Region and Lhasa.

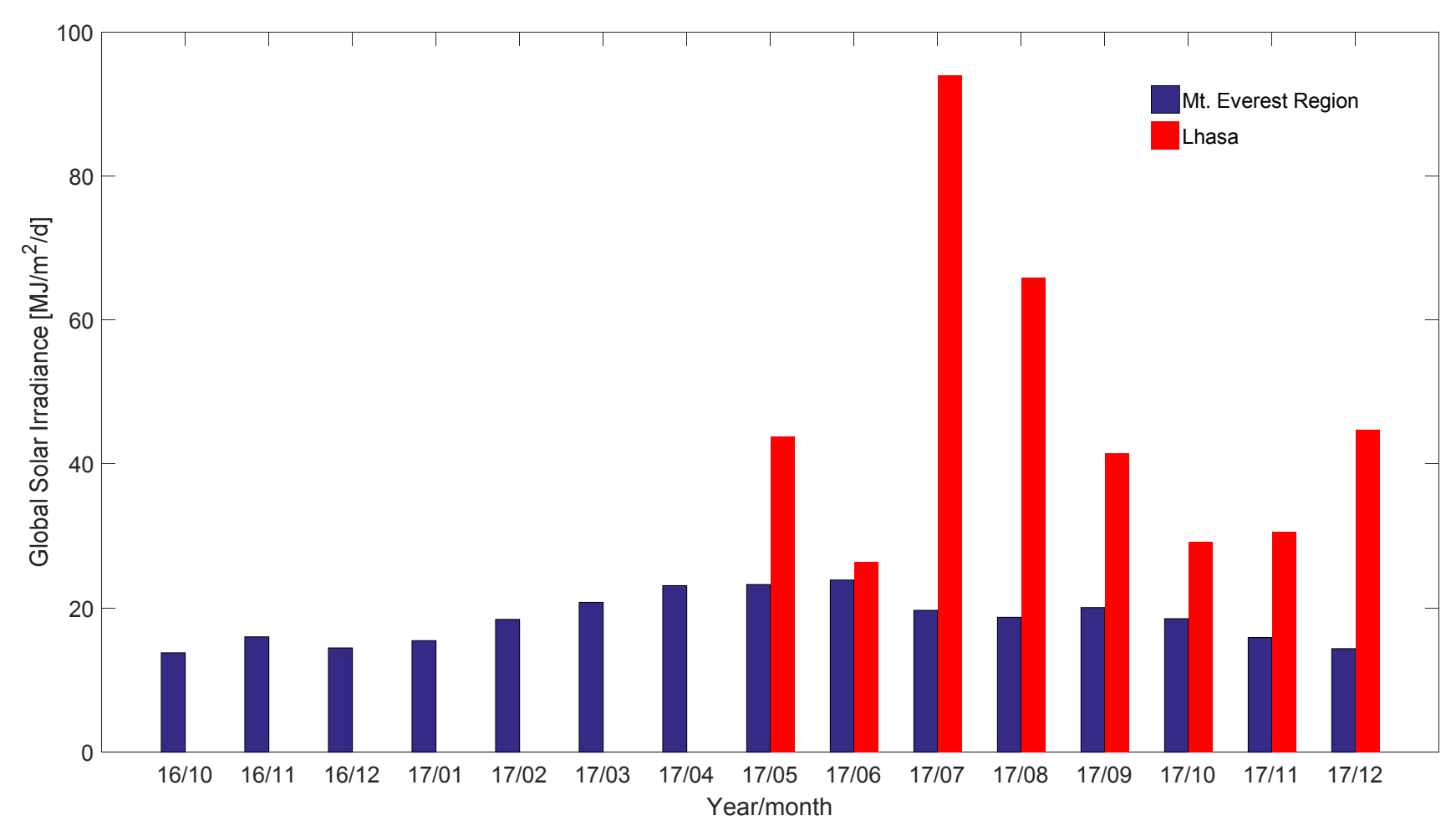

Figure 4. Monthly averaged daily global horizontal irradiance in the Mt. Everest Region and Lhasa.

We also analyzed monthly averaged daily global horizontal irradiance to see how the irradiance are distributed within a month. Figure 4 shows the distribution characteristics for each month during the observation period. The values are vary from $13.8 \mathrm{MJ} / \mathrm{m}^{2} / \mathrm{d}$ to $94.0 \mathrm{MJ} / \mathrm{m}^{2} / \mathrm{d}$. It vividly depicted that monthly averaged daily global horizontal irradiance of Lhasa exceeds the Mt. Everest Region, the maximum monthly averaged daily global horizontal irradiance of Lhasa is 4.8 times that of Mt. Everest Region (on July, 2017).

\subsection{Solar Spectral Irradiance in Mt. Everest Region}

We present measurements results of solar spectral 
irradiance in the Mt. Everest Region. The solar spectral irradiance was measured for the first time in this critical environment to see the characteristics of solar spectrum over the region. It contains rich information on the atmospheric composition over the sky. Figure 5 is ground-based measurement results for the solar spectrum wave-length between $320-950 \mathrm{~nm}$ at every ten minutes during the sun rise to local noon (UTC 1:00 to UTC 6:30) on 24 January, 2017. Figure 6 shows the solar UV spectrum for the same duration and the same day. The diagrams depicted that there are no UV irradiance in wavelength lower than $300 \mathrm{~nm}$ even such a high altitude region. The intensities of the solar spectrum increases with the sun rises, reaches the maximum value of 1.36 $\mathrm{W} \cdot \mathrm{m}^{-2} \cdot \mathrm{nm}^{-1}$ at the wavelength of $476.6 \mathrm{~nm}$ at UTC $6: 20: 00$ for that day, but the growing steps are slowing down with the sun rises. The depressions in the spectrum are due to absorption of $\mathrm{O}_{3}, \mathrm{O}_{2}$, and $\mathrm{H}_{2} \mathrm{O}$ molecules and Rayleigh scattering etc. The absorption wavelength of $\mathrm{O}_{3}, \mathrm{O}_{2}$, and $\mathrm{H}_{2} \mathrm{O}$ molecules are shown on Figure 7. We made a comparison among the highest spectrum measured in the Mt. Everest region and the standard solar spectrum at AM0 (spectrum at outside of the atmosphere) as well as solar spectrum at AM1.5. It shows that even in the winter time, closed to winter solstice, the surface solar spectrum in that region are still very high, close to the standard ones. Our measurements at other places in Tibet shows that during the summer surface spectrum could be higher than the two standard spectrum in the longer wavelength region. Therefore, we can conclude that there are rich solar energy resources in the Mt. Everest region.

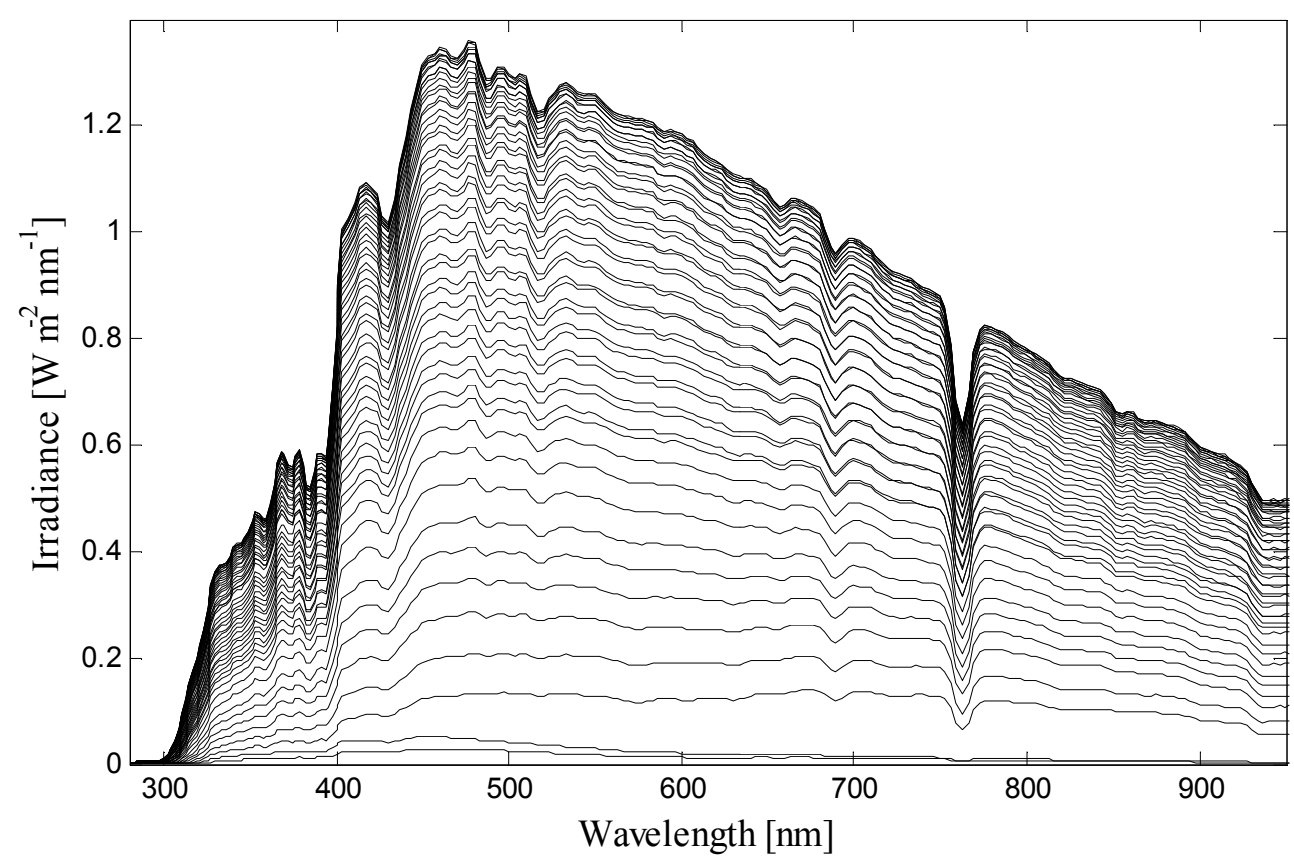

Figure 5. Ground solar spectrum in the Mt. Everest region.

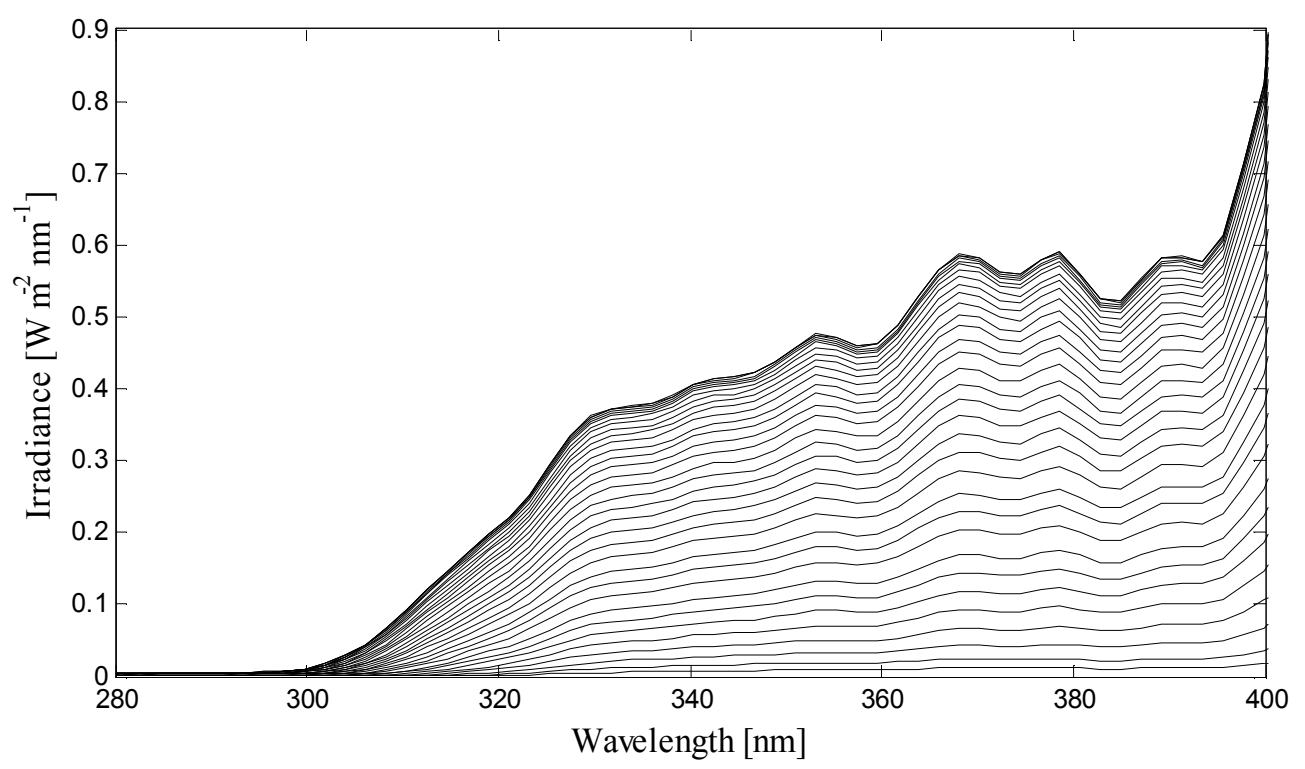

Figure 6. Ground ultraviolet spectrum in the Mt. Everest region. 


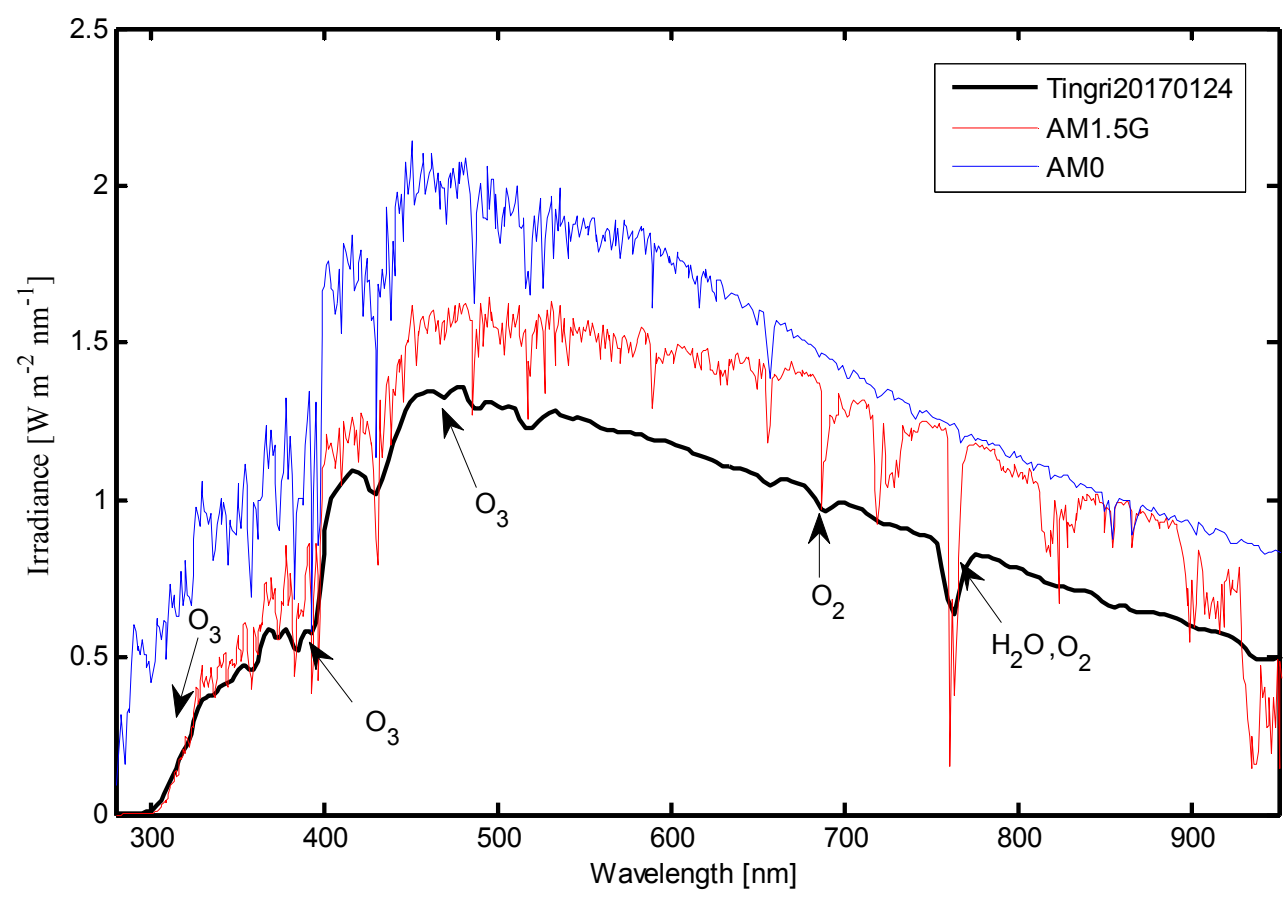

Figure 7. Comparison among measured spectrum and spectrums of AMO and AM1.5. in the Mt. Everest Region.

\subsection{Solar UV Irradiance in Mt. Everest Region}

It is to be thought that there are strong solar UV radiation in the Mt. Everest region, and it strongly impacts on the ecological environment and human health for this region. In order to protect the natural environment of Mt. Everest region, our research on the solar UV radiation and its impact factors was started around ten years ago. In this paper we present a few results as part of the solar radiation resources performed with NILU-UV Irradiance Meters. Figure 8 shows daily maximums of dose rates for UVA $(320 \sim 400 \mathrm{~nm})$ and UVB (280-320nm) from 2008 to 2017 in that region. There are missing data during 2013-2014 due to instrument problem. It shows extreme UV doses during summer time, the highest value of dose rates for UVA and UVB reached $137 \mathrm{~W} / \mathrm{m}^{2}$ and $11.4 \mathrm{~W} / \mathrm{m}^{2}$ respectively. The ratio of UVB to UVA is about $5.37 \%$ to $13.72 \%$, with an average of $7.57 \%$ in the region. The impacts of strong solar UVA and UVB on environments, materials and human health are well known.

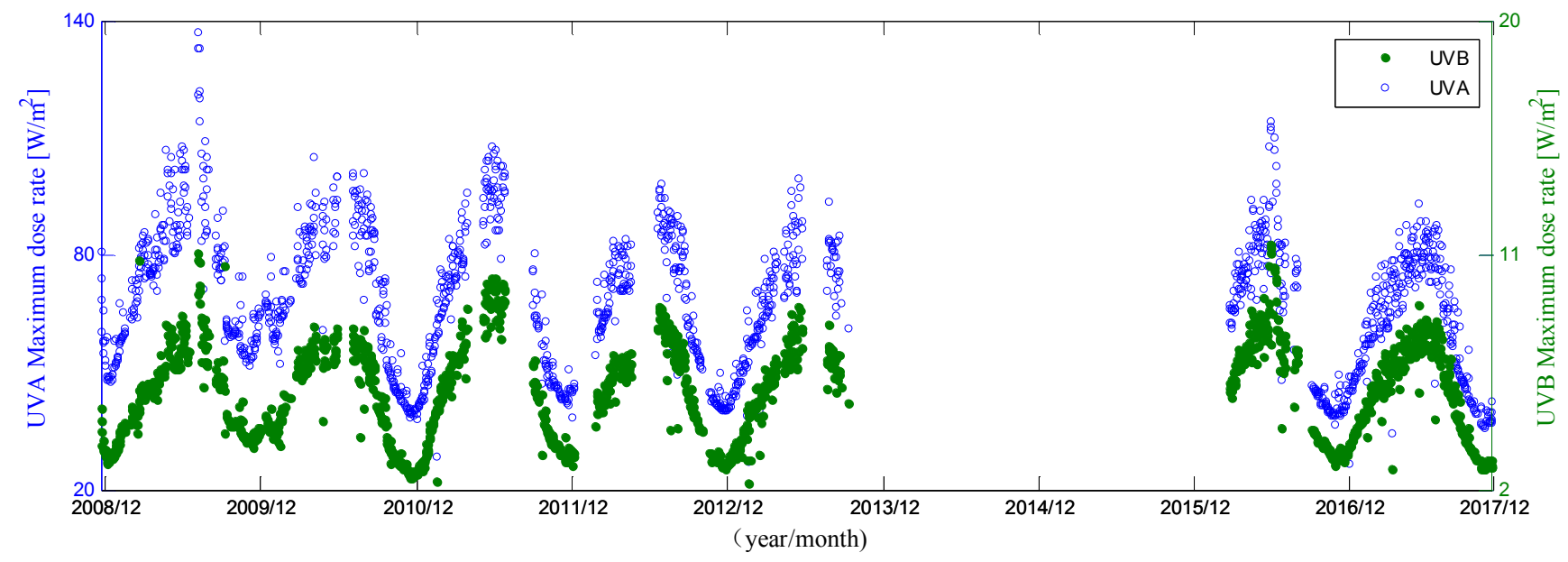

Figure 8. The daily maximum dose rate of solar UVA and UVB radiation in Mt. Everest region.

To study the impact factors of solar UV radiation over the Mt. Everest region, we analyzed local noon solar UV dose rates, total ozone column (TOC) and cloud transmittance (CLT) for each day as seen in Figure 9. The sky over the Mt.
Everest region is extremely clean, almost no aerosol, the main influence factors for the UV radiation are zone and clouds. Ozone absorbs solar UVB radiation, and clouds scatter both UVA and UVB radiation effectively. 

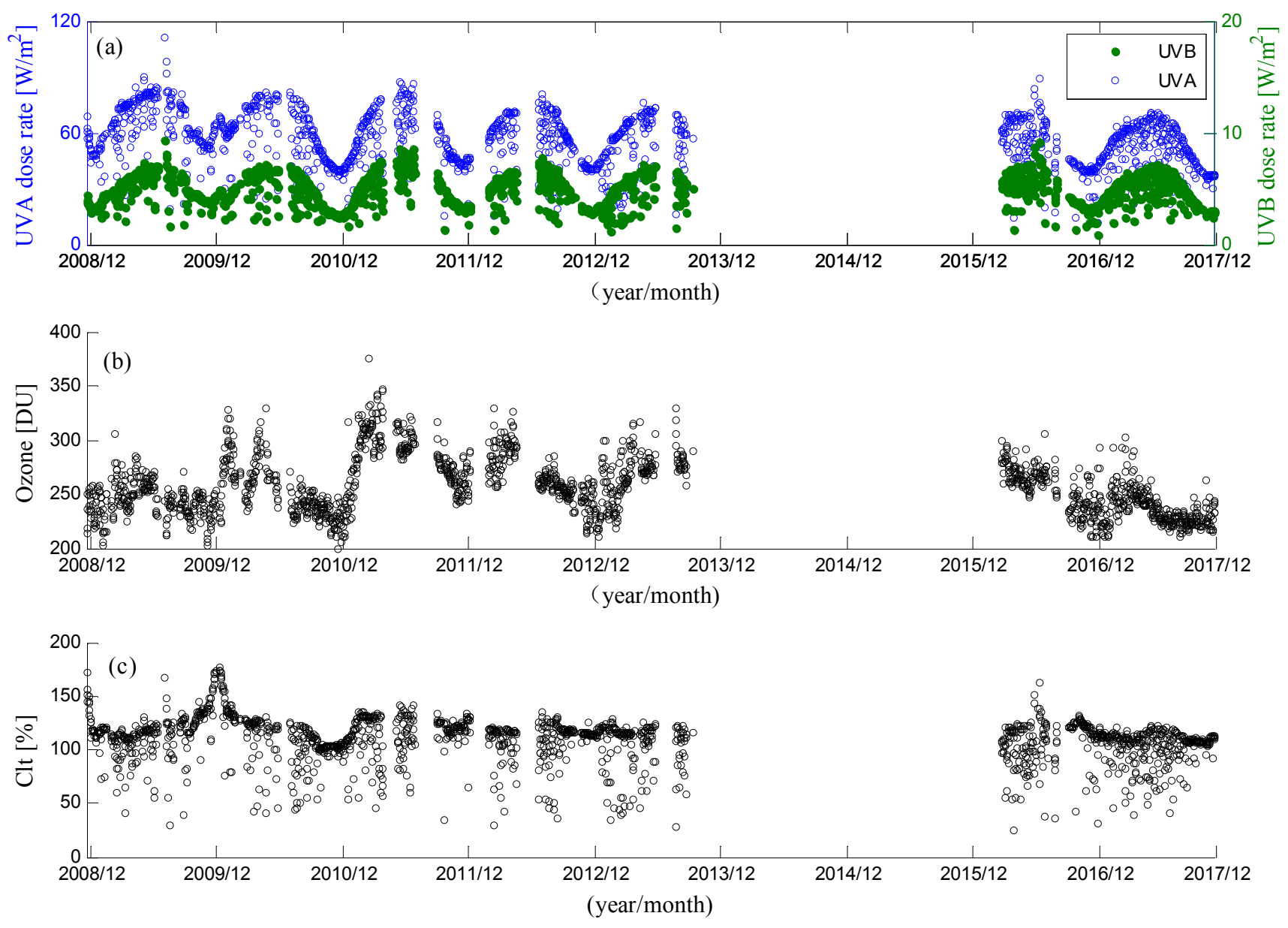

Figure 9. Solar UV dose rates, total ozone column and cloud transmittance at local noons in the Mt, Everest region.

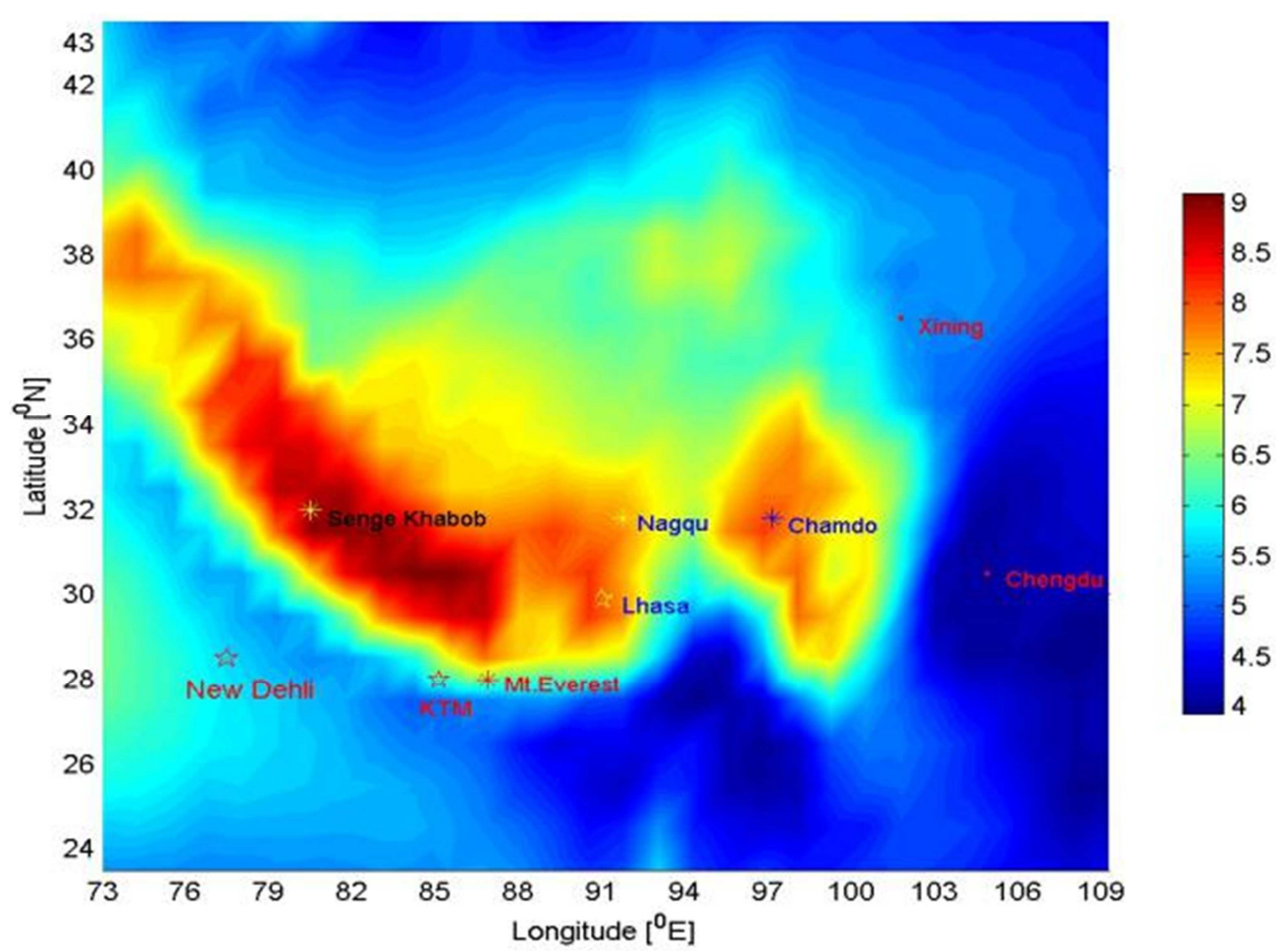

Figure 10. Spatial distribution of the summer mean daily erythemal UV dose $\left[\mathrm{kJ} / \mathrm{m}^{2} /\right.$ day $]$ averaged for 21 years across the Tibetan Plateau and its neighboring areas. 
The analysis show that the average value of dose rates for solar UVA and UVB at the noons are about $55.52 \mathrm{~W} / \mathrm{m}^{2}$ and $4.77 \mathrm{~W} / \mathrm{m}^{2}$ respectively during the observation period. The NILU-UV Irradiance Meters also provide the TOC and CLT at the same time. Figure 9 also shows the daily variation of the TOC and CLT at the local noons. The value of TOC at the noons varies from 200 DU to 376.1 DU during the observation period. TOC reaches the highest in the spring and the lowest in the autumn over sky of the particular region. The average value of the cloud transmittance at the noons is about $109.72 \%$, means the sky is mostly in clear condition. The CLT reaches the highest in winter due to clear sky condition and lowest value in summer due to the precipitation in the summer. We also present spatial distribution of the summer (May - August) mean (averaged for 21 years) daily erythemal UV dose $\left[\mathrm{kJ} / \mathrm{m}^{2} /\right.$ day $]$ across the Tibetan Plateau and its neighboring areas by using data from the TOMS (Total Ozone Mapping Spectrometer) satellite for the periods $1979-1992$ and 1997-2003. Figure 10 shows daily erythemal UV dose level in the Mt. Everest region, it shows that from Kathmandu to the north, including Mt. Everest, the daily erythemal UV dose increases very rapidly with the altitude. The averaged erythemal UV dose for the Mt. Everest region is around $6.5-7.0 \mathrm{~kJ} / \mathrm{m}^{2} /$ day in summer. However, it is not the highest value even if it has very high altitude, the highest value appears to the north in the Tibetan side, reached over $9 \mathrm{~kJ} / \mathrm{m}^{2} /$ day as seen in the Figure 10 . This is due to the clouds, humidity, or dry weather make the Tibetan side stronger radiation. Figure 10 also indicates how the solar energy distribution is over Himalayan region, including the Mt. Everest region.

\section{Conclusion}

Research on solar radiation in the Mt. Everest is great interests for people in many fields. The current study presents some preliminary or basic information and properties on the global horizontal irradiance, solar spectrum, solar UVA and UVB dose rates in Mt. Everest region through in situ observation. It is concluded that there is a sufficient amount of solar energy even in the winter time due to highly favorable climatic conditions like the presence of lower humidity at higher altitude. The measurements show that the daily solar radiation flux density frequently exceeds the solar constant $\left(1368 \mathrm{~W} / \mathrm{m}^{2}\right)$ during summer, the highest value recorded during the measurement period was $1500 \mathrm{~W} / \mathrm{m}^{2}$. Extremely strong solar UV dose rates are also recorded, the recorded maximum dose rates of UVA and UVB were $137 \mathrm{~W} / \mathrm{m}^{2}$ and $11.4 \mathrm{~W} / \mathrm{m}^{2}$ respectively. These results are only preliminary, In particular, solar spectrum observation is far from sufficient, much more research and observation are needed to show more systematic conclusion.

\section{Acknowledgements}

The research is supported by the National Natural Science
Foundation of China (project code: 41867041), and the Department of Science and Technology of Tibet Autonomous Region (project code: ZDZX2019000025), and by Tibet University (projuct named: Solar energy resources and its utilization in Tibet).

\section{References}

[1] R Rondanelli, A Molina, M Falvey, the Atacama Surface Solar Maximum. Bulletin of the American Meteorological Society [J], 2015, 96 (3): 405-418.

[2] Pinker R T, Laszlo I. Modeling Surface Solar Irradiance for Satellite Applications on a Global Scale. [J]. Journal of Applied Meteorology, 1992, 31 (2): 194-211.

[3] Wild M, Gilgen H, Roesch A. From dimming to brightening: decadal changes in solar radiation at Earth's surface.[J]. Science, 2005, 308 (5723): 847-850.

[4] BK Bhattarai, B Kjeldstad, TM Thorseth, A Bagheri. Erythemal dose in Kathmandu, Nepal based on solar UV measurements from multichannel filter radiometer, its deviation from satellite and radiative transfer simulations. Atmospheric Research Volume 85, Issue 1, July 2007, Pages 112-119.

[5] Poudyal K N, Bhattarai B K, Sapkota B, et al. Estimation of Global Solar Radiation Using Clearness Index and Cloud Transmittance Factor at Trans-Himalayan Region in Nepal [J]. Energy \& Power Engineering, 2012, 4 (6): 415-421.

[6] KN Poudyal, BK Bhattarai, BK Sapkota, B Kjeldstad, NR Karki. Estimation of Global Solar Radiation using Pyranometer and NILU-UV Irradiance Meter at Pokhara Valley in Nepal. Journal of the Institute of Engineering, 2014, $9(1)$.

[7] Norsang G, Chen Y C, Pingcuo N, et al. Comparison of ground-based measurements of solar UV radiation at four sites on the Tibetan Plateau [J]. Applied Optics, 2014, 53 (4): 736-47.

[8] Jin Y M, Norsang Gelsor, Tsoja Wangmu, et al. Observation of solar radiation in Ali, Tibet [J]. HEILONGJIANG SCIENCE, 2019, 10 (02): 28-34.

[9] ZHOU Yi, Norsang Gelsor, Tsoja Wangmu, et al. Ground-based measurements of solar spectrum in Tibet [J]. Journal of Earth Environment, 2018, 9 (02): 193-199.

[10] Norsang Gelsor, Jin Y M, Tsoja Wangmu, et al. Ground-Based Measurements of Global Solar Radiation and UV Radiation in Tibet [J]. Spectroscopy and Spectral Analysis, 2019, 39 (06): 1683-1688.

[11] Dahlback A, Gelsor N, Stamnes J J, et al. UV measurements in the 3000-5000 m altitude region in Tibet [J]. Journal of Geophysical Research Atmospheres, 2007, 112 (D9).

[12] Zhao D, Norsang, Tsoja Wangmu, et al. Measurements of Solar UV Radiation in Lhasa, Tibet [J]. Journal of Atmospheric and Environmental Optics, 2018, 13 (02): 81-87.

[13] Liu Juan, Tsoja Wangmu, Norsang Gelsor, et al. Observation of Solar Erythemal Ultraviolet Radiation on Clear Days in Tibet [J]. Acta Optica Sinica, 2020, 40 (19): 27-35. 
[14] Norsang G, Kocbach L, Stamnes J, et al. Spatial Distribution and Temporal Variation of Solar UV Radiation over the Tibetan Plateau [J]. Applied Physics Research, 2011, 3 (1).

[15] Gelsor N, Pingcuo N, Wangmu T, et al. Solar UV Irradiance Measurements at Four Sites in Tibet [J]. Journal of the Institute of Engineering, 2012, 8 (3).

[16] Chen Y C, Norsang G, Pingcuo N, et al. Solar UV radiation measurements across the Tibetan Plateau [C]. International Radiation Symposium on Radiation Processes in the. American Institute of Physics, 2013: 848-851.
[17] Høiskar, B. A. K., R. Haugen, T. Danielsen, A. Kylling, K. Ed-vardsen, A. Dahlback, B. Johnsen, M. Blumthaler, and J. Schreder (2003), Multichannel moderate-bandwidth filter instrument for measurement of the ozone-column amount, cloud transmittance, and ultraviolet dose rates, Appl. Opt., 42 (18), 3472-3479, doi: 10.1364/AO.42.003472.

[18] Dahlback, A. (1996), Measurements of biologically effective UV doses, total ozone abundances, and cloud effects with multichannel, moderate bandwidth filter instruments, Appl. Optics, 35 (33), 6514-6521, doi: 10.1364/AO.35.006514. 